\title{
Molecular Profiling in Lung Biopsies of Human Pulmonary Allografts to Predict Chronic Lung Allograft Dysfunction
}

Danny Jonigk, ${ }^{* \dagger}$ Nicole Izykowski, ${ }^{*}$ Johanna Rische, ${ }^{*}$ Peter Braubach, ${ }^{*}$ Mark Kühnel, ${ }^{\ddagger}$ Gregor Warnecke, ${ }^{\dagger \S}$ Torsten Lippmann, ${ }^{*}$ Hans Kreipe, ${ }^{*}$ Axel Haverich, ${ }^{\dagger \S}$ Tobias Welte, ${ }^{\dagger \uparrow}$ Jens Gottlieb, ${ }^{\dagger \uparrow}$ and Florian Laenger ${ }^{\star \dagger}$

From the Institutes of Pathology* and Functional and Applied Anatomy ${ }^{\ddagger}$ and the Departments of Thoracic Surgery ${ }^{\S}$ and Respiratory Medicine, ${ }^{\llbracket}$ Hanover Medical School, Hanover; and the Biomedical Research in Endstage and Obstructive Lung Disease, ${ }^{\dagger}$ the Hanover Division of the German Center for Lung Research, Gießen, Germany

Accepted for publication August 28, 2015.

Address correspondence to Danny Jonigk, M.D., Institute of Pathology, Hannover Medical School, Carl-NeubergStrasse 1, D-30625 Hanover, Germany. E-mail: jonigk danny@mh-hannover.de.

\begin{abstract}
Chronic lung allograft dysfunction (CLAD) is the main reason for poor long-term outcome of lung transplantation, with bronchiolitis obliterans (BO) representing the predominant pathological feature. $\mathrm{BO}$ is defined as a progressive fibrous obliteration of the small airways, thought to be triggered by a combination of nonimmune bronchial injury and alloimmune and autoimmune mechanisms. Because biopsy samples are too insensitive to reliably detect $\mathrm{B} 0$ and a decline in lung function test results, which is clinically used to define CLAD, does not detect early stages, there is need for alternative biomarkers for early diagnosis. Herein, we analyzed the cellular composition and differential expression of 45 tissue remodelingassociated genes in transbronchial lung biopsy specimens from two cohorts with 18 patients each: patients who did not develop CLAD within 3 years after transplantation (48 biopsy specimens) and patients rapidly developing CLAD within the first 3 postoperative years (57 biopsy specimens). Integrating the mRNA expression levels of the five most significantly dysregulated genes from the transforming growth factor- $\beta$ axis (BMP4, IL6, MMP1, SMAD1, and THBS1) into a score, patient groups could be confidently separated and the outcome predicted $(P<0.001)$. We conclude that overexpression of fibrosis-associated genes may be valuable as a tissue-based molecular biomarker to more accurately diagnose or predict the development of CLAD. (Am J Pathol 2015, 185: 3178-3188; http://dx.doi.org/10.1016/j.ajpath.2015.08.016)
\end{abstract}

Chronic lung allograft dysfunction (CLAD) occurs in approximately $50 \%$ of patients within 5 years after transplantation and is primarily responsible for the poor long-term outcome of lung transplantation (LTx) compared with other solid organ grafts. ${ }^{1}$

CLAD is clinically defined by a sustained decline of respiratory function test results. ${ }^{2}$ This criterion is rather un-specific, though, because alternative causes of functional impairment, such as acute cellular rejection (ACR) or infection, have to be excluded by simultaneous histological and microbiological testing. ${ }^{3}$ Moreover, lung function testing as a diagnostic parameter is relatively insensitive, because a significant amount of functional lung capacity has to be (irrevocably) lost before becoming clinically apparent. CLAD usually manifests 2 to 3 years after LTx, presenting as a variable, but relentless, deterioration of lung function with poor response to the few therapeutic modalities available. $^{2}$

The most prevalent morphological feature in CLAD patients is a progressive fibrous remodeling of the small airways, termed bronchiolitis obliterans (BO). ${ }^{4-6}$ Because of its patchy and discontinuous distribution, $\mathrm{BO}$ frequently escapes histological detection by transbronchial biopsies (TBBs), rendering conventional tissue-based diagnostics in CLAD patients insensitive. Still, TBBs are routinely sampled, because they represent, in combination with the clinical assessment of the transplant, the gold standard for monitoring graft function. ${ }^{7-9}$ Their added value lies in the detection and subsequent treatment of clinically

Supported by the Deutsche Forschungsgemeinschaft grant JO 743/2-1 (D.J. and F.L.), the German Center for Lung Research, and SFB 738.

Disclosures: None declared. 
silent rejection episodes, thus abolishing a potential risk factor for the development and propagation of CLAD. ${ }^{10,11}$

Because currently available treatment options, like macrolide antibiotics, cytoreductive drugs, or switch of immunosuppressive regimens, usually allow stabilization, but not normalization, of pulmonary function, emphasis has been placed on early detection, and potential prevention, of CLAD. ${ }^{12,13}$ Therefore, additional biomarkers culled from blood, lavage, or tissue would be valuable as diagnostic adjuncts to conventional histology and lung function testing. Because the documented success of treating CLAD by macrolide antibiotics at least partially hinges on the manipulation of cytokine signaling in fibrogenesis, ${ }^{10}$ unraveling the signal pathways activating myofibroblasts appears promising to uncover potential biomarkers for early CLAD.

Remodeling of the small airways follows a succession of epithelial injury, autoimmune and alloimmune responses, and recruitment, proliferation, and activation of myofibroblasts with excessive matrix production and deposition. ${ }^{14-16}$ Among the signaling pathways regulating myofibroblasts, the equilibrium of extracellular matrix (ECM) turnover is controlled by matrix metalloproteinases (MMPs), their inhibitors (tissue inhibitors of matrix metalloproteinases), and various cytokines, like bone morphogenetic proteins (BMPs), and other members of the transforming growth factor (TGF)- $\beta$ superfamily. ${ }^{17-21}$ Induction of TGF- $\beta 1$ and post-receptor Sma and Mad-related proteins (SMADs) represents a converging pathway that incorporates other profibrotic mediators, such as fibroblast growth factor-2, tumor necrosis factor- $\alpha$, and endothelin- $1 .{ }^{15,22,23}$

To generate additional biomarkers, TBBs have so far been mostly neglected; predominantly bronchoalveolar lavage (BAL) and blood samples have been analyzed by enzyme-linked immunosorbent assays and radioimmunoassays and cell counts. Elevated numbers of neutrophils, circulating fibrocytes, and helper $\mathrm{T}$ cells (with a decrease of T-regulatory cells), as well as increased levels of a multitude of cytokines are associated with the development of CLAD. Although some of these studies were designed prospectively, overall they were hampered by their rather limited number of patients and missing follow-up studies (Table 1). ${ }^{7,19,23-45}$

Analyzing explanted lung allografts by laser-assisted microdissection, we have previously shown that myofibroblasts in $\mathrm{BO}$ lesions are both recipient and donor derived and that airway remodeling in transplanted and non-transplanted patients shares significant molecular traits, such as an up-regulation of pivotal TGF- $\beta 1$, BMPs, or plasminogen activator inhibitor 1 (SERPINE1). ${ }^{7,22,46}$ Yet, we also found distinct expression patterns, which set BO lesions in CLAD apart from obliterative airway remodeling in non-transplanted patients. Moreover, we could describe a dysregulated expression of fibrosisassociated genes in morphologically still inconspicuous parenchyma of the lung explant, a field effect only delimitable on the molecular, not on the histological, level. These markers included, among others, proinflammatory chemokine (C-C motif) ligand 5 (regulated on activation normal $\mathrm{T}$ cell expressed and secreted), BMP4, MMP14, and tissue inhibitor of matrix metalloproteinases $1 .^{7,22}$

These findings open up the possibility of improving the value of tissue-based diagnosis in lung transplants by including molecular data for earlier and more accurate identification of patients at risk of developing BO.

Thus, we evaluated the concept of tissue-based molecular prediction of CLAD in TBB from human pulmonary allografts in two cohorts of clinically well-defined patients, with early-onset CLAD and long-term CLAD-free survival, respectively.

\section{Materials and Methods}

\section{Patient Selection and Materials}

We retrospectively analyzed lung biopsy specimens sampled in the first year after LTx from two patient cohorts: patients, identified via the biopsy program at Hanover Medical School's (Hanover, Germany), who rapidly developed CLAD (as defined by a continuous $>20 \%$ decrease in forced expiratory volume in 1 second from baseline) in the first 3 years after LTx (CLAD) and patients with comparable clinicopathological data, but without development of CLAD (within the same observation period; stable). The former group encompassed 18 patients (male/ female ratio, 11:7) with a mean age at transplantation of 34.9 (range, 17 to 56) years. Clinical definition and staging of CLAD were performed according to current guidelines. ${ }^{47}$ All pulmonary function tests were performed according to the guidelines of the European Respiratory Society. ${ }^{48} \mathrm{~A}$ total of 48 lung biopsy specimens (range, 1 to 7 biopsy specimens per patient) sampled 7 to 363 days after LTx were analyzed for this cohort.

The stable cohort consisted of 18 patients (male/female ratio, 10:8) with a mean age at transplantation of 46.7 (range, 19 to 63 ) years. A total of 57 lung biopsy specimens (range, 2 to 5 biopsy specimens per patient) taken 27 to 364 days after LTx were analyzed for the control group. A mean of 2.5 (range, 1 to 7) biopsy specimens per patient were analyzed for the CLAD group, and 3.2 (range, 2 to 5) for the stable group. End-stage cystic fibrosis, emphysema, and idiopathic pulmonary fibrosis (in descending order) were the leading causes for transplantation, and a combination of cyclosporin A and mycophenolat-mofetil or tacrolimus and mycophenolat-mofetil were the most common immunosuppressants used in both patient groups. Because not all patients had undergone TBB at uniform time intervals (as a result of missed surveillance biopsy specimens because of infection or additional indicationdriven biopsy specimens), biopsy (molecular) data were pooled per patient and per group, respectively, and not analyzed longitudinally. 
Table 1 Previous Publications on Molecular Analysis of Factors Associated with the Occurrence of B0 in Lung-Transplanted Patients

\begin{tabular}{|c|c|c|c|c|}
\hline Author (year) & BO/control & Material & Investigated parameters & Method \\
\hline Devouassoux et al $(2001)^{24}$ & $4 / 4$ & TBB & $\begin{array}{l}\text { HLA class I antigen, Ki- } 67 \text {, very late } \\
\text { antigen- } 4 \text {, integrins }\end{array}$ & $\mathrm{IHC}$ \\
\hline $\begin{array}{l}\text { Reynaud-Gaubert } \\
\text { et al }(2002)^{25}\end{array}$ & $8 / 13$ & BAL & IL8, MCP1, CCL5, BAL cell count & ELISA and differential cell count \\
\hline Meloni et al $(2004)^{26}$ & $8 / 36$ & $\begin{array}{l}\text { BAL } \\
\text { serum } \\
(\mathrm{TBB})\end{array}$ & $\begin{array}{l}\text { MCP1, TGF- } \beta, \text { IFN- } \gamma \text {, IL8, IL10, IL12, CCL5, } \\
\text { infection, BAL cell count, cellular } \\
\text { rejection }\end{array}$ & $\begin{array}{l}\text { ELISA, differential cell count, } \\
\text { and TBB (only for rejection) }\end{array}$ \\
\hline Hübner et al (2005) $)^{28}$ & $8 / 12$ & BAL (TBB) & MMP9, TIMP1, BAL cell count & ICC, ELISA, and zymography \\
\hline Fields et al $(2006)^{29}$ & $20 / 20$ & Blood & sCD30 & ELISA \\
\hline Lu et al $(2006)^{30}$ & $11 / 9$ & $\mathrm{BAL}(\mathrm{TBB})$ & $\begin{array}{l}\text { IL1 } \beta, \text { CD40LG, TNFSF11, TNFSF9, TNF, } \\
\text { IL2, FasL, TNFSF7, LTA, RPL13A, } \\
\text { PDGFB, VEGF, BMP6, FGF2, FGF5, ACTB* }\end{array}$ & $\begin{array}{l}\text { RNA microarray ( } 96 \text { targets) and } \\
\text { differential cell count }\end{array}$ \\
\hline $\begin{array}{l}\text { Vanaudenaerde } \\
\text { et al }(2008)^{32}\end{array}$ & $36 / 42$ & $B A L$ & $\begin{array}{l}\text { mRNA: IL8, IL17, IL23, TGF- } \beta \text {; protein: } \\
\text { IL1 } \beta, \text { IL2, IL6, IL8, IL17, IL23, TGF- } \beta \text {; } \\
\text { BAL cell count }\end{array}$ & $\begin{array}{l}\text { RT-PCR, ELISA, and differential } \\
\text { cell count }\end{array}$ \\
\hline Golocheikine et al (2008) ${ }^{33}$ & $9 / 9$ & Blood & sCD30 & ELISA \\
\hline Neurohr et al (2009) & $16 / 47$ & $\mathrm{BAL}(\mathrm{TBB})$ & SLPI, IL8, BAL cell count ( $\%$ NG) & ELISA and differential cell count \\
\hline Salama et al $(2010)^{23}$ & $30 / 30$ & Blood/BAL/TBB & Endothelin-1 & ELISA (blood) and RT-PCR (TBB) \\
\hline Bhorade et al $(2010)^{35}$ & $6 / 14$ & Blood/BAL & F0XP3 $^{+}$T-cells, CCL17, CCL22 & FACS and ELISA \\
\hline LaPar et al $(2011)^{36}$ & $10 / 29$ & Blood & Circulating fibrocyte level & FACS \\
\hline Jonigk et al $(2011)^{7}$ & $24 / 5$ & $\begin{array}{l}\text { Explanted } \\
\text { lung } \\
\text { allografts }\end{array}$ & $\begin{array}{l}\text { BMP4, BMPR2, LOX, MMP14, PLAU, CCL5, } \\
\text { THBS1, TIMP1 }\end{array}$ & RNA microarray ( 45 target genes) \\
\hline Shah et al $(2013)^{41}$ & $60 / 46$ & Blood & SRAGE & ELISA \\
\hline Borthwick et al $(2013)^{42}$ & $26 / 26$ & BAL & TNF- $\alpha$, IL1 $\beta$, IL8, BAL cell count & ELISA and differential cell count \\
\hline Jaksch et al $(2014)^{43}$ & $57 / 85$ & Blood & YKL40 & ELISA \\
\hline Xu et al $(2015)^{44}$ & $10 / 10$ & PBMC & $\begin{array}{l}\text { miRNAs of the TGF- } \beta \text { and B-cell receptor } \\
\text { signal pathway*,† }\end{array}$ & RT-PCR \\
\hline Brugiere et al $(2015)^{45}$ & $19 / 44$ & BAL/TBB/blood & $\begin{array}{l}\text { HLA-G, sHLA-G (TGF- } \beta \text {, IL6. IL8, MCP-1, } \\
\text { CXCL10, CCL5, IL17, IL10, GM-CSF, TNF- } \alpha, \\
\text { IFN- } \gamma, \text { CXCL9, IL13) }\end{array}$ & $\begin{array}{l}\text { IHC (HLA-G), ELISA, and } \\
\quad \text { Luminex }\end{array}$ \\
\hline Heijink et al (2015) & $20 / 20$ & BAL & $\begin{array}{l}\text { MMP1, MMP2, MMP3, MMP7, MMP8, } \\
\text { MMP9, MMP12, MMP13, TIMP1, TIMP2 }\end{array}$ & Luminex \\
\hline
\end{tabular}

Significantly changed markers are highlighted in bold.

*Only significantly changed markers.

${ }^{\dagger}$ Among others.

${ }^{\ddagger}$ No analysis between $\mathrm{B} 0 /$ control group reported.

$\mathrm{ACTB}, \beta$-actin; $\mathrm{BAL}$, bronchoalveolar lavage; $\mathrm{BMP}$, bone morphogenetic protein; BMPR, bone morphogenetic protein receptor; $\mathrm{B} 0$, bronchiolitis obliterans; $\mathrm{CCL}$, C-C chemokine ligand; CD40LG, CD40 ligand; CXCL10, interferon $\gamma$-induced protein 10; ECP, eosinophilic cationic protein; ELISA, enzyme-linked immunosorbent assay; FACS, fluorescence-activated cell sorter; FasL, Fas ligand; FGF1, fibroblast growth factor 1; FOXP3, forkhead box P3; GM-CSF, granulocyte macrophage colonystimulating factor; HLA, human leukocyte antigen; ICC, immunocytochemistry; IFN, interferon; IHC, immunohistochemistry; LTA, lymphotoxin- $\alpha$; LOX, lysyl oxidase; MCP1, monocyte chemotactic protein; MIP, macrophage inflammatory protein; MIG (CXCL9), monokine induced by $\gamma$ interferon; MMP, matrix metalloproteinase; MPO, myeloperoxidase; NG, neutrophilic granulocyte; PDGFB, platelet-derived growth factor subunit B; PLAU, plasminogen activator (urokinase); RPL13A, 60S ribosomal protein L13a; sCD30, soluble CD30; SLPI, secretory leukocyte protease inhibitor; sRAGE, soluble receptor for advanced glycation end product; TBB, transbronchial biopsy; TGF, transforming growth factor; THBS1, thrombospondin-1; TIMP1, tissue inhibitor of matrix metalloproteinases 1 ; TNF- $\alpha$, tumor necrosis factor- $\alpha$; TNFSF7, TNF ligand superfamily member 7; VEGF, vascular endothelial growth factor; YKL40, chitinase-like glycoprotein. 


\section{Sample Preparation}

\section{Histopathological Evaluation}

The formalin-fixed and paraffin-embedded TBBs were processed as follows: for routine histopathological investigation, serially cut sections were prepared for hematoxylin and eosin, Elastica van Gieson, and periodic acid-Schiff reaction staining. The biopsy specimens were evaluated by two experienced histopathologists (D.J. and F.L.), according to the latest International Society for Heart and Lung Transplantation (ISHLT) classification, with special emphasis on inflammatory changes (see below). The analysis was handled according to the requirements of the local ethics committee (Hanover Medical School's ethics committee vote 2050-2013). We assessed the size of the biopsy particles (scored as number of $\times 100$ and $\times 200$ magnification fields per biopsy) and the percentage of alveolar parenchyma overall. Biopsy specimens that did not fulfill the minimum requisite amount of alveolated lung tissue (minimum of 100 alveoli with precapillary and post-capillary blood vessels per high-power field) were excluded from the study.

\section{Grading of Rejection and Airway Inflammation}

Grading of rejection and airway inflammation was performed according to the current ISHLT criteria (A0, no acute cellular rejection; A2, mild acute cellular rejection; A3, moderate acute cellular rejection; A4, severe acute cellular rejection; $\mathrm{Bx}$, airway inflammation cannot be assessed; B0, no small airway inflammation; B1R, low-grade small airway inflammation; or B2R, high-grade small airway inflammation). Moreover, we assessed the overall density of the inflammatory infiltrate in bronchi and bronchioli [no inflammation (score, 0), inflammatory cells only delimitable at high magnification $(\times 400$; score, 1$)$, inflammatory cells well recognizable at medium magnification $(\times 200$; score, 2$)$, and high density of the inflammatory infiltrate well visible even at low magnification $(\times 100$; score, 3$)] .{ }^{2}$ For each patient, the maximum ISHLT A and B scores were tabulated. ACR was summarized to not present ( $\mathrm{A} 0$ ) and present ( $\mathrm{A} 1$ or higher), as was small airway inflammation (B0 and B1R or higher, respectively). The resulting data were compared by Fisher's exact test.

\section{Alveolar Macrophages}

Furthermore, we graded the amount of intra-alveolar macrophages semiquantitatively [no macrophages $(\times 400$; score, 0$)$, sparse macrophages only delimitable at high magnification $(\times 400$; score, 1$)$, macrophages well recognizable at medium magnification $(\times 200$; score, 2$)$, and high density of macrophages with a desquamative interstitial pneumonia-like (DIP) aspect, well visible even at low magnification $(\times 100$; score, 3$)$ ]. Alternatively, we also performed a direct count on the basis of a CD68 staining (PGM-1; Dako, Hamburg, Germany): after identification and registration of macrophage hot spots, we counted the number of macrophages per sectioned alveolus in 20 adjacent alveoli within the main hot spots.

\section{RNA Extraction and cDNA Generation}

After histomorphological and immunohistochemical evaluation, the whole remaining biopsy tissue was cut into sections $(10 \mu \mathrm{m}$ thick) and suspended overnight in a proteinase $\mathrm{K}$ digestion solution. RNA was isolated using phenol-chloroform extraction, followed by ethanol precipitation via our established protocol. RNA $(10 \mu \mathrm{L})$ was transcribed into cDNA using the High Capacity cDNA Reverse Transcription Kit (Applied Biosystems, Waltham, MA), following the manufacturer's guidelines. 7,49

\section{Low-Density Arrays}

To analyze the mRNA expression of 45 tissue remodeling and myofibroblast activation-associated genes and three reference genes (Supplemental Table S1), the cDNA was evaluated by real-time PCR (7900HT Fast Real-Time PCR system) using TaqMan-based low-density/high-throughput arrays. Target genes were selected on the basis of our previous analyses of $\mathrm{BO}$ lesions, laser microdissected from explanted human pulmonary allografts. ${ }^{7,22}$ The low-density arrays contained primers with an amplicon size of $100 \mathrm{bp}$ or less and were spotted eightfold into a 384-well plate, which facilitated synchronous analysis of eight samples per PCR run. Accordingly, the low-density arrays were recorded using 7900 HT SDS software version 2.3 Rev C (Applied Biosystems) to calculate the CT values. ${ }^{7}$

\section{Statistical Analysis}

Gene expression values were converted to relative expression (using the $\Delta C T$ method with polymerase- $2 \alpha$ as endogenous reference and relative expression calculated as $2-\Delta C T$ ). Relative expression values of genes not detected in RT-PCR were set to 0 . Gene expression values were compared between groups with the Wilcoxon test. All tests were regarded as exploratory, with no correction for multiple hypothesis testing.

\section{Scoring of Gene Expression in Lung Biopsy Specimens}

The variable importance for the mRNA expression levels of 45 remodeling-associated genes was estimated by random forest classification analysis [implemented by the R package random forest version 4.6-7 (http://www.r-project.org)]. ${ }^{50}$ The five highest ranked genes were selected for further analysis. Three target genes (IL4, IL13, and IL17A) with low expression in the CLAD and the stable patient group were discarded beforehand. To simplify further testing, the 95th percentile of the relative expression values in controls was used as a cutoff. If the relative expression of the gene of interest was higher than the cutoff, 1 point; otherwise, 0 points were awarded. Finally, all points for the established five genes of interest (see Results) were added together, resulting in a score with a minimum of 0 and a maximum of 5 points. All calculations were performed with $\mathrm{R}$ version 3.1 (http://www. r-project.org) on an IBM-compatible personal computer running Windows 7 (32 bit). Up-regulated genes were mapped onto pathways and biological functions using Ingenuity 


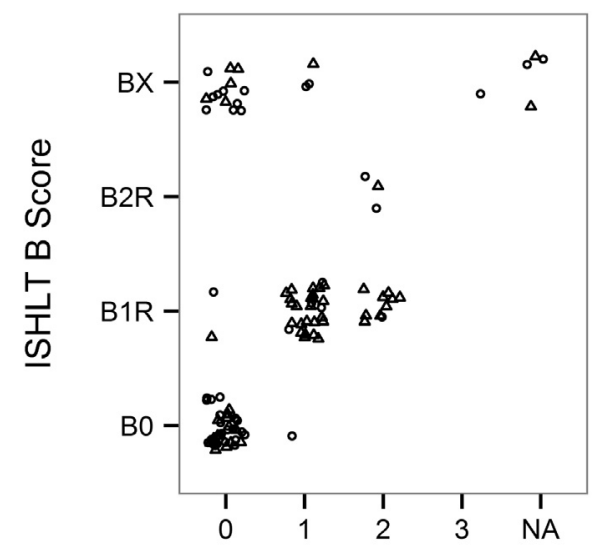

\section{Bronchiolar Wall Inflammatory Infiltration}

Figure 1 Correlation of bronchial and bronchiolar wall inflammatory infiltration (score, 0 to 3 ) with the International Society for Heart and Lung Transplantation B scores in the chronic lung allograft dysfunction (CLAD; open circles) and the stable groups (open triangles). B0, no small airway inflammation; B1R, low-grade small airway inflammation; B2R, high-grade small airway inflammation; $\mathrm{Bx}$, airway inflammation cannot be assessed; $\mathrm{NA}$, not available.

pathway analysis software version 24718999 (Qiagen, Venlo, the Netherlands).

\section{Immunohistochemistry}

To assess the complementary protein expression, immunohistochemical staining for the five highest ranked genes was performed, following our established protocol.

\section{Analysis of Macrophage Counts}

Count data were analyzed with a negative binomial generalized mixed model [R-package lme4 1.1-7 (http://www. r-project.org)], treating the patient as a random effect to account for overdispersion and multiple observations (biopsy specimens) per patient. Furthermore, the presence of macrophage hotspots [defined as clusters of macrophages delimitable at low-power magnification $(\times 100)]$ was recorded. A binomial generalized mixed model (lme4) was used to test for differences in hotspot presence. ${ }^{50}$

\section{Results}

We retrospectively analyzed lung biopsy specimens sampled from two patient cohorts: long-term survivors, who did not develop CLAD in the first 3 years after LTx (stable; 18 patients, 57 biopsy specimens), and patients who rapidly developed CLAD within the same observation period (18 patients, 48 biopsy specimens).

\section{ISHLT Scores}

\section{ISHLT A Scores}

Overall, more patients in the stable group $(n=10)$ experienced an episode of ACR (A1 or above), compared with the CLAD group $(n=4)$. However, this difference was not statistically significant [odds ratio (OR), 3.31; 95\% CI, 0.65-20.14; $P=0.158]$.

\section{ISHLT B Scores}

There were significantly more stable patients with low-grade small airway inflammation (ISHLT-B) than CLAD patients (OR, 35.91; 95\% CI, 3.56-1919; $P<0.001$ ).

\section{ISHLT C Scores}

No biopsy of our CLAD group contained part of a BO lesion (all C0).

\section{Airway Inflammatory Infiltrates}

Paralleling the findings for ISHLT B scores, biopsy specimens of the stable group showed higher scores for bronchial/ bronchiolar wall inflammatory infiltrates (mean score, 0.82; range, 0 to 2), compared with the CLAD group (mean score, 0.37 ; range, 0 to 3 ). The infiltrate scores correlate positively with the ISHLT B scores $(\tau=0.86, P<0.0001)$ (Figure 1$)$.

\section{Intra-Alveolar Macrophages}

Alveolar macrophage (AM) counts were 59\% (95\% CI, $44 \%-80 \%$ ) lower in biopsy specimens of CLAD patients, compared with stable patients $(P<0.001)$. Mean values were 60.0 AMs/20 alveolar spaces (interquartile range, 27.0 to 86.5) for the CLAD group and 89.7 AMs/20 alveolar spaces (interquartile range, 57.0 to 115.0) for the stable group (Figures 2 and 3).

These counts, on the basis of immunohistochemical marking of AM, showed a moderate correlation with the macrophage score by semiquantitative estimation (score, 0 to $3 ; r=0.38, P<0.001)$ after the removal of outliers $(r=0.29, P<0.01)$. AM hotspots could be detected more frequently in biopsy specimens of stable patients $(59.7 \%)$ than in CLAD patients (37.5\%), showing only a trend toward statistical significance $(P=0.058)$. Within the same patients, there were no relevant changes in macrophage density over time or in between the available TBB.
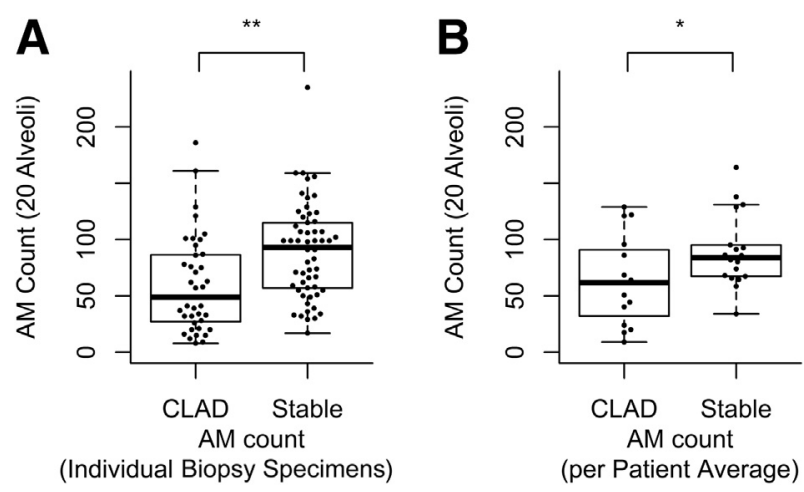

Figure 2 Alveolar macrophages (AMs) per 20 alveoli in the chronic lung allograft dysfunction (CLAD) and the stable groups, shown per individual biopsy (A) and per patient average (B). ${ }^{*} P<0.05,{ }^{*} P<0.01$. 


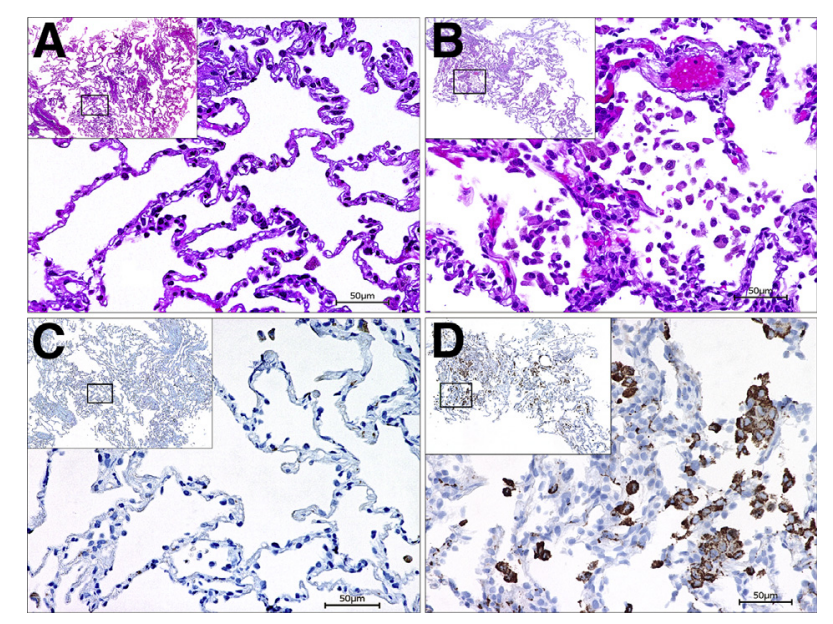

Figure 3 Alveolar macrophages stained by hematoxylin and eosin (A and B) and immunohistochemically against $\mathrm{CD}^{+} 8^{+}$(clone PGM-1; C and D) in transbronchial lung biopsy specimens of patients who rapidly developed chronic lung allograft dysfunction (CLAD; $\mathbf{A}$ and $\mathbf{C}$ ) and patients who did not develop CLAD in the first 3 years after lung transplantation (stable; $\mathbf{B}$ and $\mathbf{D}$ ). Note the prominent intra-alveolar content of macrophages in the stable group compared with the CLAD group. Boxed areas in insets indicate areas of higher magnification in the main panel. Original magnification, $\times 400$ (A-D, main images); $\times 100$ (A-D, insets).

\section{Gene Expression in CLAD and Stable Groups: Random Forest Analysis}

In TBB from the CLAD group, we found a significant upregulation of 22 genes, compared with the stable group (Supplemental Table S1).

Of the differentially expressed genes outlined above, the five statistically (and biologically) most important variables for separation of the CLAD and stable groups, as determined by random forest analysis, were BMP4, IL6, MMP1, $S M A D 1$, and THBS1. Relative expression values for all their gene products were significantly higher in biopsy specimens of CLAD than stable patients (Figures 4 and 5).

\section{Classification of Lung Biopsy Specimens}

The relative cutoff values $\left(95^{\text {th }}\right.$ percentile of relative expression in stable patients) were 0.17 for $I L 6,0.02$ for MMP1, 0.65 for SMAD1, 4.78 for THBS1, and 0.69 for
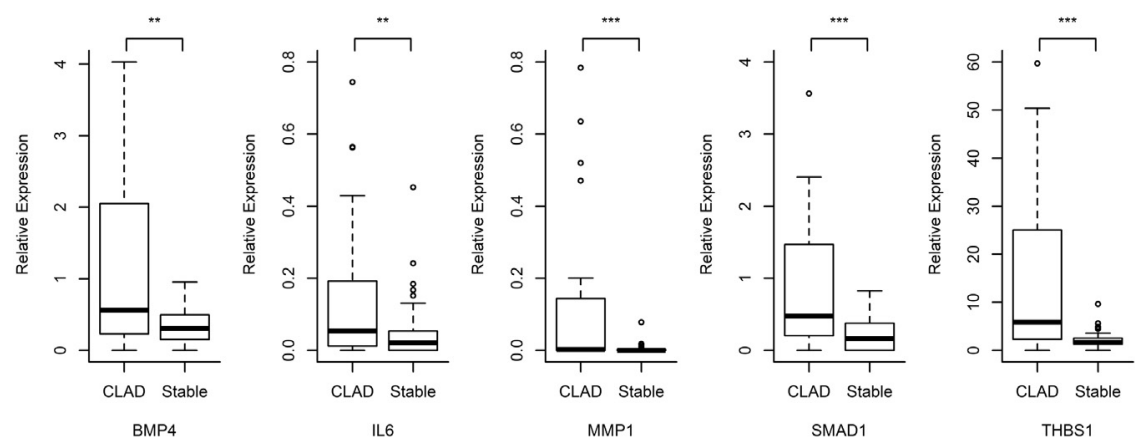

Figure 4 Relative mRNA expression levels for IL-6, matrix metalloproteinase 1 (MMP1), Sma and Mad-related protein 1 (SMAD1), thrombospondin 1 (THBS1), and bone morphogenetic protein 4 (BMP4) in lung biopsy specimens of rapid-onset chronic lung allograft dysfunction (CLAD) and the stable groups. ${ }^{* *} P<0.01,{ }^{* * *} P<0.001$. 


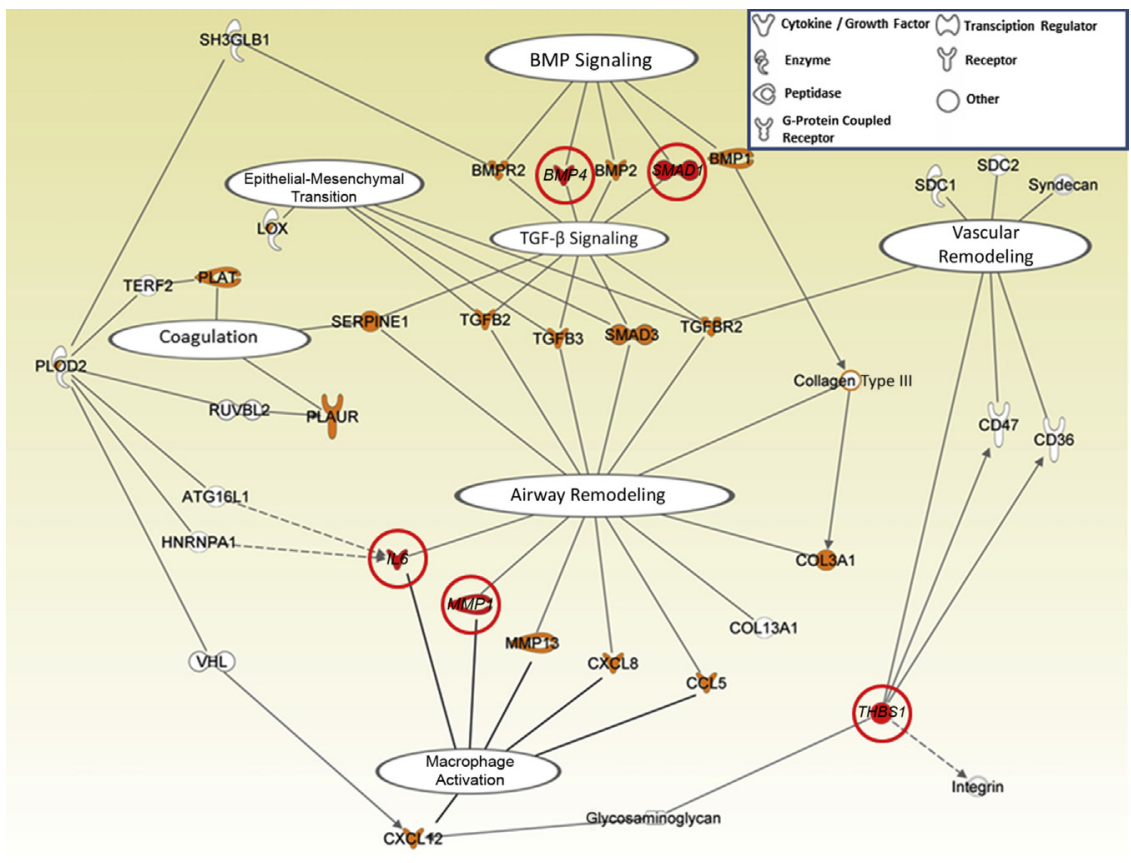

Figure 5 Visualization of pathways and functions affected via chronic lung allograft dysfunction (CLAD)-associated and up-regulated genes. Genes that were found to be up-regulated in biopsy specimens of CLAD patients were mapped onto pathways and biological functions (orange). Of these, the five most important for separation of the rapid-onset CLAD and the stable groups were BMP4, IL6, MMP1, SMAD1, and THBS1 (marked and highlighted in red). ATG16L1, autophagy-related protein 16-1; BMP, bone morphogenetic protein; BMPR2, bone morphogenetic protein receptor type II; CCL5, chemokine (C-C motif) ligand 5; CD36, fatty acid translocase; $\mathrm{CD} 47$, integrin associated protein; COL3A1, collagen, type III, alpha 1; CXCL8, IL-8; CXCL12, CXC-motiv-chemokin 12; HNRNPA1, heterogeneous nuclear ribonucleoprotein A1; LOX, lipoxygenase; MMP, matrix metallopeptidase; PLAT, plasminogen activator, tissue; PLAUR, plasminogen activator, urokinase receptor; PLOD2, procollagenlysine; RUVBL2, RuvB-like AAA ATPase 2; SDC, syndecan; Serpine1, plasminogen activator inhibitor-1; SH3GLB1, SH3-domain GRB2-like endophilin B1; Terf2, telomeric repeat-binding factor 2; TGF, transforming growth factor; THBS1, thrombospondin 1; VHL, Von Hippel-Lindau tumor suppressor.

Conventional histopathological and ISHLT criteria (ACR, presence and density of airway inflammation, and remodeling) revealed no significant differences between the two groups, underlining their lack of sensitivity regarding CLAD. Nevertheless, airway inflammation and recurrent episodes of ACR have been described as risk factors for the future development of CLAD, a correlation we also did not find in our groups. This is most likely because of our limited observation period and the fact that at Hanover Medical School, unlike other transplant centers, clinically silent rejection episodes are diagnosed because of the established surveillance biopsy program and are immediately and aggressively treated. ${ }^{47,51-54}$

Regarding the potential use of cytokine profiles and expression data to predict patient outcome after LTx, several groups have reported, in $>20$ publications, data concerning a multitude of factors involved in airway remodeling (Table 1). However, so far, no biomarker pattern has been introduced into routine clinical practice. ${ }^{7,19,23-45}$

In our work, we found an up-regulation of a larger number of mediators governing different fields of function, such as epithelial-mesenchymal transition, vascular remodeling, hemostasis, and macrophage recruitment, and activation in biopsy specimens from patients of the CLAD group (Supplemental Table S1). Particularly, so far, mostly unreported gene products associated with the BMP-TGF- $\beta$ axis and particularly myofibroblast activation showed a differential expression between the two patient groups and emerged as promising diagnostic markers to identify patients at risk for developing CLAD. These potential biomarkers included BMP4, IL6, MMP1, SMAD1, and THBS1 (Figure 5).

Because most comparable approaches of molecular testing focused on BAL samples, parallel testing of biopsy specimens and complementary lavages would have been desirable. Unfortunately, biobanked BAL specimens adequately preserved for reliable molecular testing were not available for these retrospective cohorts.

A continuous increase of proinflammatory cytokines has been put forward in recent publications as preceding and predicting CLAD. ${ }^{26,55,56}$

The central role of proinflammatory IL6 in tissue remodeling, (autoimmune) pulmonary disease, and pulmonary vascular aging has been recognized for some time. ${ }^{57-59}$ Its important role in LTx failure has been recognized more recently: IL6 elevation in blood and BAL of recipients and even in the graft before LTx has been shown to be associated with the

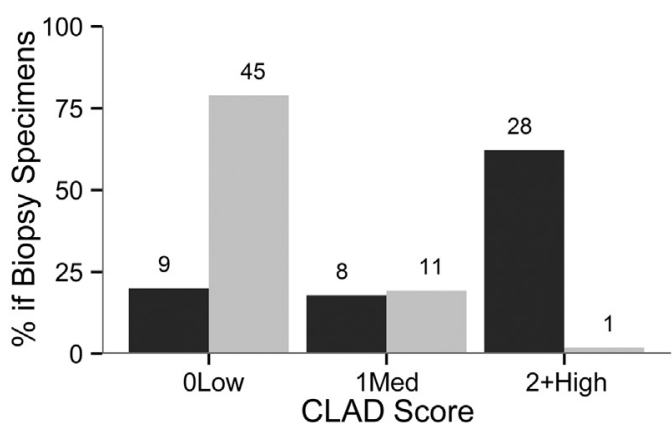

Figure 6 Classification of transbronchial biopsy specimens according to the chronic lung allograft dysfunction (CLAD) score (points awarded for the increased expression of IL-6, matrix metalloproteinase 1, Sma and Mad-related protein 1, thrombospondin 1, and bone morphogenetic protein 4 were summed up in every biopsy specimen of every patient, resulting in the respective (LAD score of the biopsy specimens). The point score was condensed to 0,1 , and 2 or higher $(2+)$, because values of $>2$ did not aid in discriminating the rapid-onset CLAD (dark gray bars) and the stable (light gray bars) groups. Number of biopsy specimens is given. 
occurrence of more frequent rejection episodes, earlier manifestation of BO syndrome, and restrictive allograft syndrome and a greater chance of death. ${ }^{31,39}$ This outcome seems to be the sequelae of an exaggerated inflammatory response with consecutive amplified alloimmunity, type 17 helper T-cell activation, proliferation, and induction of TGF- $\beta$-dependent airway remodeling. ${ }^{31,55,60}$ These findings, especially regarding the overexpression of IL6, match our own.

Likewise, we found THBS1, a member of the thrombospondin family of multifunctional proteins, a strong differentiator between the CLAD and stable groups and describe its potential role and diagnostic value in CLAD for the first time. In health and disease, THBS1 is secreted into the ECM and interacts with at least a dozen cellular receptors, among them syndecans, integrins, integrin-associated protein, and fatty acid translocase (CD36), regulating cell migration and ECM remodeling. ${ }^{61}$ More recent findings suggest an activating THBS1-TGF- $\beta$ axis in fibrosing and inflammatory lesions in visceral organs, emphasizing its potential use as a biomarker in fibrosing lung diseases. ${ }^{61}$ This corresponds to in vitro and in vivo findings that THBS1 activates latent TGF- $\beta$ secreted by AMs via interaction with plasmin and CD36. It could be shown that THBS1 overexpression correlated with the onset and exacerbation of idiopathic interstitial pneumonias, particularly with a decrease in vital capacity. ${ }^{61-64}$

Of the other mediators we found strongly associated with BO, BMP4 is of particular interest. The role of the BMPs, particularly BMP4, in lung disease is far from clear: an MMP-mediated effect of BMP4 on soft tissue hemostasis in humans, direct inhibition of epithelial cell proliferation and differentiation, and induction and repression of ECM maturation have all been described. ${ }^{20,21}$ In experimental systemic application in chronic allograft nephropathy, BMP4 and BMP7 inhibited the transformation of fibroblasts to activated myofibroblasts, consecutive ECM deposition, and smooth muscle metaplasia via the activin receptor-like kinase 1 (ALK1)/SMAD1/5 pathway. ${ }^{20,21,65,66}$ So, the exact role of BMP4 and BMP7 in tissue remodeling in adults remains unclear, particularly in the lungs, and we are the first to address it in regard to diagnosing CLAD. Most likely, BMP4, produced by the remnant respiratory cells, acts profibrotic or antifibrotic in a concentration-dependent manner via the TGF- $\beta$ pathway, with subsequent phosphorylation of cytosolic SMADs by a BMP receptor kinase. ${ }^{21}$ Likewise, BMP7 is known to counteract TGF- $\beta$-induced epithelialmesenchymal transition and facilitate epithelial regeneration in visceral organs. Somewhat comparable, SMAD1 can also act in a profibrotic and antifibrotic manner: SMAD1, and potentially also SMAD5 and SMAD8, are directly recruited by Alk1, an alternative TGF- $\beta$ receptor, to drive the expression of a subset of profibrotic genes, via the Alk1/ SMAD1 axis.

Of special interest in lung remodeling is the transition of fibroblasts to myofibroblasts, which is paralleled by the expression of smooth muscle actin and smooth muscle myosin. ${ }^{16}$ In this way, the SMAD1/5/8 complex is a common downstream mediator of TGF- $\beta$ signaling in primary and secondary fibrosing pulmonary diseases, such as idiopathic pulmonary fibrosis or pulmonary manifestation of scleroderma. ${ }^{65,67,68}$ Likewise, it has been shown in vitro that some of the antifibrotic effects of the tyrosine kinase inhibitor imatinib (Glivec; Novartis, Basel, Switzerland) are mediated by inhibition of SMAD1, with subsequent repression of TGF- $\beta$-mediated connective tissue growth factor and collagen type I and formation of ECM. ${ }^{65}$

All of the mediators listed above regulate TGF- $\beta$, the lynchpin of tissue remodeling in the airways. Of the downstream effectors, we found MMP1 to be an indicator of impending BO. MMP1 is able to break down fibrillar collagens I, II, and III. ${ }^{14,17}$ Correspondingly, increased expression of MMP1 in chronic obstructive pulmonary disease corresponds to the degree of disintegration of alveolar septa and the loss of vital capacity. ${ }^{14}$ However, tissue degradation by MMPs also unveils autoantigens, such as $\mathrm{K}-\alpha 1$-tubulin and type- $\mathrm{V}$ collagen, which, in a vicious circle, trigger and strengthen an autoimmune response, initially leading to MMP activation. ${ }^{11,12,69}$ Furthermore, it has also been demonstrated that the degradation of structural cells and ECM liberates and activates dormant signaling molecules like pro-TGF- $\alpha$ and other members of the epidermal growth factor family. These, in a positive feedback loop, induce the TGF- $\beta$ cascade and promote further tissue breakdown. . $^{21,65,70}$

Accordingly, down-regulation of MMP1 is an important step in physiological wound healing, whereas lingering wounds are characterized by an uncontested overexpression. ${ }^{42,64}$ Interestingly, MMP1 has also been reported intracellularly and is thought to be vital in cell division, migration, differentiation, and, ultimately, apoptosis. ${ }^{14,17}$ This might explain the prominent up-regulation of MMP1 in progressive fibrosing diseases like idiopathic pulmonary fibrosis. ${ }^{71}$ Systematic analyses of the role of different MMPs in CLAD development in human patients have, for the most part, been performed in BAL specimens. In these, especially MMP9 has come into the center of interest, whereas an overexpression of MMP1 could not be found. ${ }^{19,27}$ The fact that we can describe an up-regulation of MMP1 in TBB of CLAD patients indicates different compartments sampled by $\mathrm{BAL}$ or TBB, and is an argument for tissue-based molecular testing in LTx patients.

In a systematic assessment of the inflammatory cells in the analyzed biopsy specimens, we found significantly more intra-alveolar macrophages in the stable group compared with the CLAD group. This principally agrees with the findings of others, who reported a decrease in macrophages in the BAL of LTx patients with manifested BO syndrome. ${ }^{27,40}$ In BAL samples, this was so far attributed to the relative increase in neutrophils and lymphocytes as the cytological hallmark of a shift toward a proinflammatory and profibrogenic microenvironment in (early) CLAD. ${ }^{63,68}$ We found a distinct up-regulation of IL6 and MMP1 only 
in the CLAD group, a signature associated with classically activated M1 macrophages. ${ }^{63,64}$ Conversely, we speculate that the low levels of these proinflammatory cytokines and enzymes in the stable group, with abundant intra-alveolar macrophages present at the same time, might point toward an alternate, and potentially beneficial, state of activation. One of these is the M2 subtype, which is associated with immunomodulation, maintenance of self-tolerance, and tissue hemostasis as well as wound healing and ECM reconstitution. ${ }^{63,64,72}$ The M1/M2 phenotypes are dynamic states, exhibited in response to exogenous or endogenous stimuli, such as TGF- $\beta$ and BMP4 and BMP7, and macrophage populations can revert from one to the other given a change of microenvironment. ${ }^{64,73}$ However, under the immunosuppressive regimen after LTx, it is known that proinflammatory IL expression is reduced in macrophages, which might lead to an inactive state, associated with inactivation of autoreactive or alloreactive T cells. ${ }^{58}$ This represents a crucial step in the decrease of cellular rejection by induction of tolerance against allo-antigens and (physiologically sequestered) auto-antigens. ${ }^{74}$ In our study, the alveolar concentration of macrophages remained stable over time, in individual patients and within patient groups and correlated inversely with the CLAD score, in contrast to all other inflammatory cells, characterized by the ISHLT score. Accordingly, the differences in concentration of intra-alveolar macrophages might reflect the levels of local inflammatory mediators in the graft in response to continuous injurious stimuli. Nonetheless, one would rather expect increased accumulation of macrophages in the transplant, because abundant macrophages are found in the inflammation-rich early BO lesions, formerly designated as active in the 1995 ISHLT formulation; these show predominantly an M1 phenotype. So, the role of AMs in the development or prevention of CLAD should be investigated more closely. Particularly the influence of different macrophage subpopulations on graft fate should be assessed by functional experiments and analysis of the cytokine micromilieu.

We conclude that further investigations on the potential use of molecular biomarkers for CLAD in TBB are warranted. On the basis of our results and of others, groups of genes from the TGF- $\beta$ axis, particularly $B M P 4, I L 6, M M P I$, $S M A D 1$, and THBS1, present themselves as promising targets and may act as predictive markers, particularly for early events contributing to the subsequent development of CLAD. Further studies should follow a prospective design and analyze TBB and complementary BAL samples at the same time.

\section{Acknowledgments}

We thank Regina Engelhardt for excellent technical support, Kais Hussein for critical remarks, Imke Zinowsky and Linda Haesler for help with clinical data, and Kristin Mitschke, Paul Borchert, and Gillian Teicke for editing assistance.

\section{Supplemental Data}

Supplemental material for this article can be found at http://dx.doi.org/10.1016/j.ajpath.2015.08.016.

\section{References}

1. Yusen RD, Edwards LB, Kucheryavaya AY, Benden C, Dipchand AI, Dobbels F, Goldfarb SB, Levvey BJ, Lund LH, Meiser B, Stehlik J: International Society for Heart and Lung Transplantation: the registry of the International Society for Heart and Lung Transplantation: thirty-first adult lung and heart-lung transplant report-2014; focus theme: retransplantation. J Heart Lung Transplant 2014, 33:1009-1024

2. Kapila A, Baz MA, Valentine VG, Bhorade SM; AIRSAC Investigators: Reliability of diagnostic criteria for bronchiolitis obliterans syndrome after lung transplantation: a survey. J Heart Lung Transplant 2015, 34:65-74

3. Weigt SS, DerHovanessian A, Wallace WD, Lynch JP 3rd, Belperio JA: Bronchiolitis obliterans syndrome: the Achilles' heel of lung transplantation. Semin Respir Crit Care Med 2013, 34:336-351

4. Barker AF, Bergeron A, Rom WN, Hertz MI: Obliterative bronchiolitis. N Engl J Med 2014, 370:1820-1828

5. Lynch JP 3rd, Weigt SS, DerHovanessian A, Fishbein MC, Gutierrez A, Belperio JA: Obliterative (constrictive) bronchiolitis. Semin Respir Crit Care Med 2012, 33:509-532

6. Baz MA, Layish DT, Govert JA, Howell DN, Lawrence CM, Davis RD, Tapson VF: Diagnostic yield of bronchoscopies after isolated lung transplantation. Chest 1996, 110:84-88

7. Jonigk D, Merk M, Hussein K, Maegel L, Theophile K, Muth M, Lehmann U, Bockmeyer CL, Mengel M, Gottlieb J, Welte T, Haverich A, Golpon H, Kreipe H, Laenger F: Obliterative airway remodeling: molecular evidence for shared pathways in transplanted and native lungs. Am J Pathol 2011, 178:599-608

8. Estenne M, Hertz MI: Bronchiolitis obliterans after human lung transplantation. Am J Respir Crit Care Med 2002, 166:440-444

9. Ward C, Snell GI, Zheng L, Orsida B, Whitford H, Williams TJ, Walters EH: Endobronchial biopsy and bronchoalveolar lavage in stable lung transplant recipients and chronic rejection. Am J Respir Crit Care Med 1998, 158:84-91

10. Vos R, Vanaudenaerde BM, Verleden SE, Ruttens D, Vaneylen A, Van Raemdonck DE, Dupont LJ, Verleden GM: Anti-inflammatory and immunomodulatory properties of azithromycin involved in treatment and prevention of chronic lung allograft rejection. Transplantation 2012, 94:101-109

11. Subramanian V, Ramachandran S, Banan B, Bharat A, Wang X, Benshoff N, Kreisel D, Gelman AE, Mohanakumar T: Immune response to tissue-restricted self-antigens induces airway inflammation and fibrosis following murine lung transplantation. Am J Transplant 2014, 14:2359-2366

12. Weber DJ, Wilkes DS: The role of autoimmunity in obliterative bronchiolitis after lung transplantation. Am J Physiol Lung Cell Mol Physiol 2013, 304:L307-L311

13. Shitrit D, Bendayan D, Gidon S, Saute M, Bakal I, Kramer MR: Long-term azithromycin use for treatment of bronchiolitis obliterans syndrome in lung transplant recipients. J Heart Lung Transplant 2005 , 24:1440-1443

14. Gosselink JV, Hayashi S, Elliott WM, Xing L, Chan B, Yang L, Wright C, Sin D, Pare PD, Pierce JA, Pierce RA, Patterson A, Cooper J, Hogg JC: Differential expression of tissue repair genes in the pathogenesis of chronic obstructive pulmonary disease. Am J Respir Crit Care Med 2010, 181:1329-1335

15. Jonigk D, Al-Omari M, Maegel L, Muller M, Izykowski N, Hong J, Hong K, Kim SH, Dorsch M, Mahadeva R, Laenger F, Kreipe H, Braun A, Shahaf G, Lewis EC, Welte T, Dinarello CA, Janciauskiene S: Anti-inflammatory and immunomodulatory 
properties of alpha1-antitrypsin without inhibition of elastase. Proc Natl Acad Sci U S A 2013, 110:15007-15012

16. Hinz B, Phan SH, Thannickal VJ, Galli A, Bochaton-Piallat ML, Gabbiani G: The myofibroblast: one function, multiple origins. Am J Pathol 2007, 170:1807-1816

17. Herrera I, Cisneros J, Maldonado M, Ramirez R, Ortiz-Quintero B, Anso E, Chandel NS, Selman M, Pardo A: Matrix metalloproteinase (MMP)-1 induces lung alveolar epithelial cell migration and proliferation, protects from apoptosis, and represses mitochondrial oxygen consumption. J Biol Chem 2013, 288:25964-25975

18. Sato M, Hwang DM, Guan Z, Yeung JC, Anraku M, Wagnetz D, Hirayama S, Waddell TK, Liu M, Keshavjee S: Regression of allograft airway fibrosis: the role of MMP-dependent tissue remodeling in obliterative bronchiolitis after lung transplantation. Am J Pathol 2011, 179:1287-1300

19. Heijink IH, Rozeveld D, van der Heide S, van der Bij W, Bischoff R, van Oosterhout AJ, van der Toorn M: Metalloproteinase profiling in lung transplant recipients with good outcome and bronchiolitis obliterans syndrome. Transplantation 2015, 99:1946-1952

20. Molloy EL, Adams A, Moore JB, Masterson JC, Madrigal-Estebas L, Mahon BP, O'Dea S: BMP4 induces an epithelial-mesenchymal transition-like response in adult airway epithelial cells. Growth Factors $2008,26: 12-22$

21. Pegorier S, Campbell GA, Kay AB, Lloyd CM: Bone morphogenetic protein (BMP)-4 and BMP-7 regulate differentially transforming growth factor (TGF)-beta1 in normal human lung fibroblasts (NHLF). Respir Res 2010, 11:85

22. Jonigk D, Theophile $\mathrm{K}$, Hussein $\mathrm{K}$, Bock O, Lehmann U, Bockmeyer CL, Gottlieb J, Fischer S, Simon A, Welte T, Maegel L, Kreipe H, Laenger F: Obliterative airway remodelling in transplanted and non-transplanted lungs. Virchows Arch 2010, 457:369-380

23. Salama M, Jaksch P, Andrukhova O, Taghavi S, Klepetko W Aharinejad S: Endothelin-1 is a useful biomarker for early detection of bronchiolitis obliterans in lung transplant recipients. J Thorac Cardiovasc Surg 2010, 140:1422-1427

24. Devouassoux G, Pison C, Drouet C, Pin I, Brambilla C, Brambilla E: Early lung leukocyte infiltration, HLA and adhesion molecule expression predict chronic rejection. Transpl Immunol 2001, 8: 229-236

25. Reynaud-Gaubert M, Marin V, Thirion X, Farnarier C, Thomas P, Badier M, Bongrand P, Giudicelli R, Fuentes P: Upregulation of chemokines in bronchoalveolar lavage fluid as a predictive marker of post-transplant airway obliteration. J Heart Lung Transplant 2002, 21: $721-730$

26. Meloni F, Vitulo P, Cascina A, Oggionni T, Bulgheroni A, Paschetto E, Klersy C, D'Armini AM, Fietta A, Bianco AM, Arbustini E, Vigano M: Bronchoalveolar lavage cytokine profile in a cohort of lung transplant recipients: a predictive role of interleukin-12 with respect to onset of bronchiolitis obliterans syndrome. J Heart Lung Transplant 2004, 23:1053-1060

27. Taghavi S, Krenn K, Jaksch P, Klepetko W, Aharinejad S: Bronchoalveolar lavage matrix metalloproteases as a sensitive measure of bronchiolitis obliterans. Am J Transplant 2005, 5:1548-1552

28. Hübner RH, Meffert S, Mundt U, Bottcher H, Freitag S, El Mokhtari NE, Pufe T, Hirt S, Folsch UR, Bewig B: Matrix metalloproteinase-9 in bronchiolitis obliterans syndrome after lung transplantation. Eur Respir J 2005, 25:494-501

29. Fields RC, Bharat A, Steward N, Aloush A, Meyers BF, Trulock EP, Chapman WC, Patterson GA, Mohanakumar T: Elevated soluble CD30 correlates with development of bronchiolitis obliterans syndrome following lung transplantation. Transplantation 2006, 82: $1596-1601$

30. Lu BS, Yu AD, Zhu X, Garrity ER Jr, Vigneswaran WT, Bhorade SM: Sequential gene expression profiling in lung transplant recipients with chronic rejection. Chest 2006, 130:847-854

31. Bharat A, Narayanan K, Street T, Fields RC, Steward N, Aloush A, Meyers B, Schuessler R, Trulock EP, Patterson GA, Mohanakumar T:
Early posttransplant inflammation promotes the development of alloimmunity and chronic human lung allograft rejection. Transplantation 2007, 83:150-158

32. Vanaudenaerde BM, De Vleeschauwer SI, Vos R, Meyts I, Bullens DM, Reynders V, Wuyts WA, Van Raemdonck DE, Dupont LJ, Verleden GM: The role of the IL23/IL17 axis in bronchiolitis obliterans syndrome after lung transplantation. Am J Transplant 2008, 8:1911-1920

33. Golocheikine AS, Saini D, Ramachandran S, Trulock EP, Patterson A, Mohanakumar T: Soluble CD30 levels as a diagnostic marker for bronchiolitis obliterans syndrome following human lung transplantation. Transpl Immunol 2008, 18:260-263

34. Neurohr C, Huppmann P, Samweber B, Leuschner S, Zimmermann G, Leuchte H, Baumgartner R, Hatz R, Frey L, Ueberfuhr P, Bittmann I, Behr J; Munich Lung Transplant Group: Prognostic value of bronchoalveolar lavage neutrophilia in stable lung transplant recipients. J Heart Lung Transplant 2009, 28:468-474

35. Bhorade SM, Chen H, Molinero L, Liao C, Garrity ER, Vigneswaran WT, Shilling R, Sperling A, Chong A, Alegre ML: Decreased percentage of CD4+FoxP3 + cells in bronchoalveolar lavage from lung transplant recipients correlates with development of bronchiolitis obliterans syndrome. Transplantation 2010, 90: $540-546$

36. LaPar DJ, Burdick MD, Emaminia A, Harris DA, Strieter BA, Liu L, Robbins M, Kron IL, Strieter RM, Lau CL: Circulating fibrocytes correlate with bronchiolitis obliterans syndrome development after lung transplantation: a novel clinical biomarker. Ann Thorac Surg 2011, 92:470-477. discussion 477

37. Reilly C, Cervenka T, Hertz MI, Becker T, Wendt CH: Human neutrophil peptide in lung chronic allograft dysfunction. Biomarkers 2011, 16:663-669

38. Wolf T, Oumeraci T, Gottlieb J, Pich A, Brors B, Eils R, Haverich A, Schlegelberger B, Welte T, Zapatka M, von Neuhoff N: Proteomic bronchiolitis obliterans syndrome risk monitoring in lung transplant recipients. Transplantation 2011, 92:477-485

39. Hall DJ, Baz M, Daniels MJ, Staples ED, Klodell CT, Moldawer LL, Beaver TM: Immediate postoperative inflammatory response predicts long-term outcome in lung-transplant recipients. Interact Cardiovasc Thorac Surg 2012, 15:603-607

40. Fisichella PM, Davis CS, Lowery E, Ramirez L, Gamelli RL, Kovacs EJ: Aspiration, localized pulmonary inflammation, and predictors of earlyonset bronchiolitis obliterans syndrome after lung transplantation. J Am Coll Surg 2013, 217:90-100. discussion 100-101

41. Shah RJ, Bellamy SL, Lee JC, Cantu E, Diamond JM, Mangalmurti N, Kawut SM, Ware LB, Christie JD: Early plasma soluble receptor for advanced glycation end-product levels are associated with bronchiolitis obliterans syndrome. Am J Transplant 2013, 13:754-759

42. Borthwick LA, McIlroy EI, Gorowiec MR, Brodlie M, Johnson GE, Ward C, Lordan JL, Corris PA, Kirby JA, Fisher AJ: Inflammation and epithelial to mesenchymal transition in lung transplant recipients: role in dysregulated epithelial wound repair. Am J Transplant 2010, 10:498-509

43. Jaksch P, Taghavi S, Klepetko W, Salama M: Pretransplant serum human chitinase-like glycoprotein YKL-40 concentrations independently predict bronchiolitis obliterans development in lung transplant recipients. J Thorac Cardiovasc Surg 2014, 148:273-281

44. Xu Z, Nayak D, Yang W, Baskaran G, Ramachandran S, Sarma N, Aloush A, Trulock E, Hachem R, Patterson GA, Mohanakumar T: Dysregulated microRNA expression and chronic lung allograft rejection in recipients with antibodies to donor HLA. Am J Transplant $2015,15: 1933-1947$

45. Brugiere O, Thabut G, Krawice-Radanne I, Rizzo R, Dauriat G, Danel C, Suberbielle C, Mal H, Stern M, Schilte C, Pretolani M, Carosella ED, Rouas-Freiss N: Role of HLA-G as a predictive marker of low risk of chronic rejection in lung transplant recipients: a clinical prospective study. Am J Transplant 2015, 15:461-471 
46. Brocker V, Langer F, Fellous TG, Mengel M, Brittan M, Bredt M, Milde S, Welte T, Eder M, Haverich A, Alison MR, Kreipe H, Lehmann U: Fibroblasts of recipient origin contribute to bronchiolitis obliterans in human lung transplants. Am J Respir Crit Care Med 2006, $173: 1276-1282$

47. Meyer KC, Raghu G, Verleden GM, Corris PA, Aurora P, Wilson KC, Brozek J, Glanville AR; ISHLT/ATS/ERS BOS Task Force Committee, ISHLT/ATS/ERS BOS Task Force Committee: An international ISHLT/ATS/ERS clinical practice guideline: diagnosis and management of bronchiolitis obliterans syndrome. Eur Respir $\mathrm{J}$ 2014, 44:1479-1503

48. Miller MR, Hankinson J, Brusasco V, Burgos F, Casaburi R, Coates A, Crapo R, Enright P, van der Grinten CP, Gustafsson P, Jensen R, Johnson DC, MacIntyre N, McKay R, Navajas D, Pedersen OF, Pellegrino R, Viegi G, Wanger J: ATS/ERS Task Force: Standardisation of spirometry. Eur Respir J 2005, 26:319-338

49. Jonigk D, Modde F, Bockmeyer CL, Becker JU, Lehmann U: Optimized RNA extraction from non-deparaffinized, laser-microdissected material. Methods Mol Biol 2011, 755:67-75

50. R Development Core Team: R: A Language and Environment for Statistical Computing. Vienna, Austria, 2008.

51. Burton CM, Iversen M, Scheike T, Carlsen J, Andersen CB: Minimal acute cellular rejection remains prevalent up to 2 years after lung transplantation: a retrospective analysis of 2697 transbronchial biopsies. Transplantation 2008, 85:547-553

52. Verleden GM, Dupont LJ, Van Raemdonck DE: Is it bronchiolitis obliterans syndrome or is it chronic rejection: a reappraisal? Eur Respir J 2005, 25:221-224

53. Kesten S, Maidenberg A, Winton T, Maurer J: Treatment of presumed and proven acute rejection following six months of lung transplant survival. Am J Respir Crit Care Med 1995, 152:1321-1324

54. Glanville AR, Aboyoun CL, Havryk A, Plit M, Rainer S, Malouf MA: Severity of lymphocytic bronchiolitis predicts long-term outcome after lung transplantation. Am J Respir Crit Care Med 2008, 177:1033-1040

55. Patella M, Anile M, Del Porto P, Diso D, Pecoraro Y, Onorati I, Mantovani S, De Giacomo T, Ascenzioni F, Rendina EA, Venuta F: Role of cytokine profile in the differential diagnosis between acute lung rejection and pulmonary infections after lung transplantation $\dagger$. Eur J Cardiothorac Surg 2015, 47:1031-1036

56. Sullivan JA, Adams AB, Burlingham WJ: The emerging role of TH17 cells in organ transplantation. Transplantation 2014, 97:483-489

57. Garcia JE, Lopez AM, de Cabo MR, Rodriguez FM, Losada JP, Sarmiento RG, Lopez AJ, Arellano JL: Cyclosporin A decreases human macrophage interleukin-6 synthesis at post-transcriptional level. Mediators Inflamm 1999, 8:253-259

58. Losa Garcia JE, Rodriguez FM, Martin de Cabo MR, Garcia Salgado MJ, Losada JP, Villaron LG, Lopez AJ, Arellano JL: Evaluation of inflammatory cytokine secretion by human alveolar macrophages. Mediators Inflamm 1999, 8:43-51

59. Alam S, Li Z, Atkinson C, Jonigk D, Janciauskiene S, Mahadeva R: Z alpha1-antitrypsin confers a proinflammatory phenotype that contributes to chronic obstructive pulmonary disease. Am J Respir Crit Care Med 2014, 189:909-931

60. Tan JL, Chan ST, Wallace EM, Lim R: Human amnion epithelial cells mediate lung repair by directly modulating macrophage recruitment and polarization. Cell Transplant 2014, 23:319-328
61. Ide M, Ishii H, Mukae H, Iwata A, Sakamoto N, Kadota J, Kohno S: High serum levels of thrombospondin-1 in patients with idiopathic interstitial pneumonia. Respir Med 2008, 102:1625-1630

62. Di Guglielmo GM: TSP-1 in lung fibrosis. J Cell Commun Signal 2010, 4:185-186

63. Grailer JJ, Haggadone MD, Sarma JV, Zetoune FS, Ward PA: Induction of M2 regulatory macrophages through the beta2-adrenergic receptor with protection during endotoxemia and acute lung injury. J Innate Immun 2014, 6:607-618

64. Ploeger DT, Hosper NA, Schipper M, Koerts JA, de Rond S, Bank RA: Cell plasticity in wound healing: paracrine factors of M1/M2 polarized macrophages influence the phenotypical state of dermal fibroblasts. Cell Commun Signal 2013, 11:29

65. Munoz-Felix JM, Gonzalez-Nunez M, Lopez-Novoa JM: ALK1Smad1/5 signaling pathway in fibrosis development: friend or foe? Cytokine Growth Factor Rev 2013, 24:523-537

66. Suzuki T, Arumugam P, Sakagami T, Lachmann N, Chalk C, Sallese A, Abe S, Trapnell C, Carey B, Moritz T, Malik P, Lutzko C, Wood RE, Trapnell BC: Pulmonary macrophage transplantation therapy. Nature 2014, 514:450-454

67. Brown M, Postlethwaite AE, Myers LK, Hasty KA: Supernatants from culture of type I collagen-stimulated PBMC from patients with cutaneous systemic sclerosis versus localized scleroderma demonstrate suppression of MMP-1 by fibroblasts. Clin Rheumatol 2012, 31:973-981

68. Alexander KA, Flynn R, Lineburg KE, Kuns RD, Teal BE, Olver SD, Lor M, Raffelt NC, Koyama M, Leveque L, Le Texier L, Melino M, Markey KA, Varelias A, Engwerda C, Serody JS, Janela B, Ginhoux F, Clouston AD, Blazar BR, Hill GR, MacDonald KP: CSF-1-dependant donor-derived macrophages mediate chronic graft-versus-host disease. J Clin Invest 2014, 124: $4266-4280$

69. Hachem RR, Tiriveedhi V, Patterson GA, Aloush A, Trulock EP, Mohanakumar T: Antibodies to K-alpha 1 tubulin and collagen V are associated with chronic rejection after lung transplantation. Am J Transplant 2012, 12:2164-2171

70. Schwartze JT, Becker S, Sakkas E, Wujak LA, Niess G, Usemann J, Reichenberger F, Herold S, Vadasz I, Mayer K, Seeger W, Morty RE: Glucocorticoids recruit Tgfbr3 and Smad1 to shift transforming growth factor-beta signaling from the $\mathrm{Tgfbr} 1 / \mathrm{Smad} 2 / 3$ axis to the Acvrl1/Smad1 axis in lung fibroblasts. J Biol Chem 2014, 289: 3262-3275

71. Konishi K, Gibson KF, Lindell KO, Richards TJ, Zhang Y, Dhir R, Bisceglia M, Gilbert S, Yousem SA, Song JW, Kim DS, Kaminski N: Gene expression profiles of acute exacerbations of idiopathic pulmonary fibrosis. Am J Respir Crit Care Med 2009, 180:167-175

72. Shen B, Liu X, Fan Y, Qiu J: Macrophages regulate renal fibrosis through modulating TGF $\beta$ superfamily signaling. Inflammation 2014 , 37:2076-2084

73. Rocher C, Singla R, Singal PK, Parthasarathy S, Singla DK: Bone morphogenetic protein 7 polarizes THP-1 cells into M2 macrophages. Can J Physiol Pharmacol 2012, 90:947-951

74. Hoves S, Krause SW, Schutz C, Halbritter D, Scholmerich J, Herfarth H, Fleck M: Monocyte-derived human macrophages mediate anergy in allogeneic T cells and induce regulatory T cells. J Immunol 2006, 177:2691-2698 